\title{
Staphylococcal Enterotoxin A
}

National Cancer Institute

\section{Source}

National Cancer Institute. Staphylococcal Enterotoxin A. NCI Thesaurus. Code C1083.

\begin{abstract}
A bacterial enterotoxin with potential immunostimulatory activity. Staphylococcal enterotoxin $A(S E A)$, a gram positive bacterial superantigen (SAg), is a potent stimulator of T-cell activation. SEA superantigen binds directly to class II major histocompatibility complex (MHC) molecules and to the $V$ beta region of the $T$-cell receptor (TCR), leading to an amplified T-cell response. In response to SEA, both CD4+ and CD8+ cells proliferate, secrete cytokines, and demonstrate enhanced cytotoxic activity against a broad range of antigens. Vaccination with the SEA protein, administered by direct transfection into tumor cells, may elicit a non-specific cytotoxic T-cell (CTL) response and result in decreased tumor cell growth.
\end{abstract}

